\title{
Efficacy and Safety of Topical 3\% Diquafosol Ophthalmic Solution for the Treatment of Multifactorial Dry Eye Disease: Meta-Analysis of Randomized Clinical Trials
}

\author{
Kiyeun Nam ${ }^{a}$ Hyun Jung Kim ${ }^{b}$ Aeri Yoo ${ }^{c}$ \\ ${ }^{a}$ Department of Physical Medicine and Rehabilitation, Dongguk University College of Medicine, \\ Goyang, South Korea; ${ }^{b}$ Department of Preventive Medicine, Korea University College of Medicine, \\ Seoul, South Korea; ${ }^{\mathrm{C} C e n t r a l ~ S e o u l ~ E y e ~ C e n t e r, ~ S e o u l, ~ S o u t h ~ K o r e a ~}$
}

\section{Keywords}

Dry eye disease - Eye drops - Efficacy · Safety - 3\% diquafosol

\begin{abstract}
Purpose: A meta-analysis was performed to evaluate the safety and efficacy of topical 3\% diquafosol in treating patients with dry eye disease (DED). Methods: Nine qualified randomized controlled trials incorporating 1,467 patients were included. Two of the reviewers selected the studies and independently assessed the risk of bias. The outcome measures were Schirmer score, tear film break-up time (TFBUT), rose bengal staining score, and corneal fluorescein staining score. To confirm the effect of diquafosol on dryness after cataract surgery, we performed a subgroup analysis according to the presence or absence of surgery. Results: We observed statistically significant improvements in scores on the Schirmer test (weighted mean difference $0.74 \mathrm{~mm}$ at 4 weeks; $95 \% \mathrm{Cl}: 0.24-1.24 ; l^{2}=0 \%$ ), fluorescein stain, rose bengal stain, and TFBUT after treatment with diquafosol compared with the group using other eye drops. As a result of the subgroup analysis of DED after cataract surgery, diquafosol was found to be more effective than the other eye
\end{abstract}

(c) 2019 S. Karger AG, Basel

E-Mail karger@karger.com www.karger.com/ore drops with regard to TFBUT and rose bengal staining. Conclusions: Topical diquafosol could be an effective treatment for DED, and also for DED after cataract surgery. Further randomized controlled trials with larger sample sizes for the different clinical types of DED are warranted to determine the efficacy and limitations of diquafosol for these different clinical types of DED.

(c) 2019 S. Karger AG, Basel

\section{Introduction}

Dry eye disease (DED) is a multifactorial disease of the ocular surface characterized by loss of homeostasis of the tear film and accompanied by ocular symptoms such as tear film instability and hyperosmolarity, ocular surface inflammation and damage, and neurosensory abnormalities [1]. It is associated with decreased tear production and abnormality of the lipid, protein, and mucin profiles. These changes may result in tear film instability with potential

Kiyeun Nam and Hyun Jung Kim contributed equally to this work. 
damage to the ocular surface, increased tear film osmolality, and subsequent inflammation of the ocular surface and are a major cause of ocular discomfort [1-3]. Current medical therapies for the management of dry eye include tear supplementation, retention, and stimulation, anti-inflammatory agents, and environmental strategies [1]. Topical application of sodium hyaluronate has been shown to confer both subjective and objective improvement in patients with DED and it is widely used in the treatment of dry eye patients. However, treatment with sodium hyaluronate alone was inadequate for the improvement of subjective or objective symptoms in some dry eye patients in a clinical setting. In particular, sodium hyaluronate could not supplement the components of tears.

Diquafosol, a pharmacological agent under investigation, is a purinergic $\mathrm{P}_{2} \mathrm{Y}_{2}$ receptor agonist that promotes fluid transfer and mucin secretion by activating $\mathrm{P}_{2} \mathrm{Y}_{2}$ receptors expressed on the ocular surface [4-6]. Diquafosol $3 \%$ eye drops have become widely available for dry eye patients and improve aqueous tear secretion in dry eye patients $[7,8]$. But there is no consensus on the efficacy of diquafosol as a clinical therapy for dry eye. Several randomized clinical trials (RCTs) have been performed concerning diquafosol and dry eye. To our knowledge, no meta-analysis has been done to provide recommendations to evaluate the treatment effects of 3\% diquafosol for dry eye. The present systemic review and meta-analysis of the results of RCTs of 3\% diquafosol eye drops for DED was undertaken to address this shortcoming.

\section{Methods}

We reviewed the evidence from published RCTs that evaluated topical 3\% diquafosol eye drops versus control eye drops for DED. We carried out a systematic review and meta-analysis according to the Cochrane review methods and reporting following the PRISMA statement [9].

\section{Data Source and Literature Source}

We searched MEDLINE, Embase, Scopus, Web of Science, and the Cochrane Central Register of Controlled Trials (CENTRAL) for all RCTs. The following search terms were used singly and in appropriate combinations: diquafosol, dry eye syndromes, and purinergic P2Y receptor agonists. The electronic searches were undertaken on November 7, 2017. We also reviewed the reference lists of the identified articles and other systematic reviews to gather additional published or unpublished data. No language or date restrictions were applied. We searched the World Health Organization International Clinical Trials Registry Platform and the database of the United States National Institutes of Health (ClinicalTrials.gov) for potentially eligible unpublished or ongoing trials. The MEDLINE, Embase, CENTRAL, Web of Science, and Scopus search strategies are presented in the online material (online suppl. Appendix; see www.karger.com/doi/10.1159/000492896 for all online suppl. material).

\section{Study Selection}

The inclusion of all studies was independently decided on by two reviewers (K.N. and A.Y.) based on the predefined selection criteria. The study selection was made by assessing the titles and abstracts. If eligibility could not be determined, the full article was screened.

\section{Inclusion and Exclusion Criteria}

RCTs were eligible for inclusion if the following criteria were satisfied. First, patients had a diagnosis of DED prior to the study and after an operation, defined as a Schirmer score without anesthesia $>0 \mathrm{~mm} / 5 \mathrm{~min}$ and $<10 \mathrm{~mm} / 5 \mathrm{~min}$; a tear film break-up time (TFBUT) $<10 \mathrm{~s}$; the presence of superficial punctate keratitis as evidenced by corneal fluorescein staining on slit-lamp examination; a total corneal fluorescein staining score $>4$ according to the National Eye Institute Industry/Workshop; or the presence of symptoms of tear film instability associated with DED, such as dryness, irritation, photophobia, tearing, and foreign body sensation. Second, patients had received treatment with topical 3\% diquafosol eye drops 4 or 6 times daily. Third, treatment with topical 3\% diquafosol eye drops had been compared head to head with artificial tears or placebo.

Studies were excluded based on one or both of the following criteria: a history of previous or concurrent use of other topical and/or oral treatments that may have interfered with the outcomes, and outcomes or data presented in a format that could not be extracted for analysis (i.e., no corresponding standard deviation [SD] was provided along with the outcome measurement or the data were presented in a qualitative manner).

\section{Data Extraction}

The two reviewers (A.Y. and K.N.) selected the studies according to the aforementioned criteria and extracted data independently using a predesigned data extraction form. The following variables were extracted from the studies: etiology of DED; type of intervention used as a control, sample size, mean age, gender, duration of follow-up, and outcome measures; mean and SD of the intervention and control groups; demographic, clinical, and treatment characteristics (e.g., number of patients in the intervention and control groups); intervention protocol type; and method of assessment. If these variables were not mentioned in the studies, we asked for the data from the authors via email.

\section{Assessment of Methodological Quality}

Two reviewers (A.Y. and K.N.) independently assessed the risk of bias (including selection bias, performance bias, detection bias, attrition bias, reporting bias, and others) for each study according to the criteria given in the Cochrane Handbook. The likely magnitude and direction of each bias was assessed, as was the likelihood of an impact on the findings. If needed, we explored the impact of the bias in a sensitivity analysis. Publication bias was not assessable for these trials. Our analysis only included 9 RCTs; thus, tests for asymmetry would be ineffective as they would be unable to differentiate chance from asymmetry. Any unresolved disagreements between the reviewers were resolved through discussion or review by the third author. 
Table 1. Characteristics of the included studies

\begin{tabular}{|c|c|c|c|c|c|c|c|c|c|c|c|}
\hline \multirow[t]{2}{*}{ Study [Ref.] } & \multirow{2}{*}{$\begin{array}{l}\text { Study } \\
\text { design }\end{array}$} & \multirow{2}{*}{$\begin{array}{l}\text { Year; } \\
\text { country }\end{array}$} & \multirow{2}{*}{$\begin{array}{l}\text { Inter- } \\
\text { vention }\end{array}$} & \multirow[t]{2}{*}{ Comparator } & \multirow{2}{*}{$\begin{array}{l}\text { Regimen; } \\
\text { duration }\end{array}$} & \multirow{2}{*}{$\begin{array}{l}\text { Specific type } \\
\text { of DES }\end{array}$} & \multirow{2}{*}{$\begin{array}{l}\text { Patients/ } \\
\text { eyes, } n\end{array}$} & \multicolumn{2}{|c|}{ Male/female, $n$} & \multicolumn{2}{|c|}{ Mean age, years } \\
\hline & & & & & & & & intervention & control & intervention & control \\
\hline Baek [11] & $\mathrm{RCT}$ & $\begin{array}{l}\text { 2016; } \\
\text { Korea }\end{array}$ & $3 \%$ DQA & $0.9 \%$ saline & $\begin{array}{l}4 \text { times; } \\
8 \text { weeks }\end{array}$ & $\begin{array}{l}\text { DES after } \\
\text { cataract OP }\end{array}$ & $34 / 34$ & $10 / 21$ & $10 / 21$ & $67.66 \pm 11.86$ & $67.66 \pm 11.86$ \\
\hline Gong [12] & $\mathrm{RCT}$ & $\begin{array}{l}\text { 2015; } \\
\text { China and } \\
\text { Singapore }\end{array}$ & $3 \%$ DQA & $0.1 \% \mathrm{HA}$ & $\begin{array}{l}6 \text { times; } \\
4 \text { weeks }\end{array}$ & DES & $489 / 978$ & $53 / 188$ & $55 / 193$ & $\begin{array}{l}\leq 64 \text { years } \\
(n=217) / \\
\geq 65 \text { years } \\
(n=24)\end{array}$ & $\begin{array}{l}\leq 64 \text { years } \\
(n=237) / \\
\geq 65 \text { years } \\
(n=11)\end{array}$ \\
\hline Hwang [13] & RCT & $\begin{array}{l}2014 ; \\
\text { Korea }\end{array}$ & $3 \%$ DQA & $0.1 \% \mathrm{HA}$ & $\begin{array}{l}4 \text { times; } \\
12 \text { weeks }\end{array}$ & $\begin{array}{l}\text { Tear } \\
\text { deficiency } \\
\text { DES }\end{array}$ & $150 / 150$ & $12 / 38$ & $10 / 40$ & $65.77 \pm 9.26$ & $63.32 \pm 8.52$ \\
\hline Kamiya [14] & $\mathrm{RCT}$ & $\begin{array}{l}\text { 2012; } \\
\text { Japan }\end{array}$ & $\begin{array}{l}3 \% \mathrm{DQA}+ \\
0.1 \% \mathrm{HA}\end{array}$ & $0.1 \% \mathrm{HA}$ & $\begin{array}{l}6 \text { times; } \\
4 \text { weeks }\end{array}$ & DES & $32 / 64$ & $5 / 27$ & $5 / 27$ & $62.6 \pm 12.8$ & $62.6 \pm 12.8$ \\
\hline Matsumoto [15] & $\mathrm{RCT}$ & $\begin{array}{l}\text { 2012; } \\
\text { Japan }\end{array}$ & $3 \%$ DQA & Placebo & $\begin{array}{l}6 \text { times; } \\
6 \text { weeks }\end{array}$ & DES & $286 / 286$ & $17 / 77$ & $18 / 76$ & $56.4 \pm 17.8$ & $56.1 \pm 17.3$ \\
\hline Park [16] & $\mathrm{RCT}$ & $\begin{array}{l}2016 ; \\
\text { Korea }\end{array}$ & $3 \%$ DQA & $0.1 \% \mathrm{HA}$ & $\begin{array}{l}6 \text { times; } \\
12 \text { weeks }\end{array}$ & $\begin{array}{l}\text { DES after } \\
\text { cataract OP }\end{array}$ & $120 / 212$ & $17 / 28$ & $10 / 39$ & $65.53 \pm 11.15$ & $65.37 \pm 10.02$ \\
\hline $\begin{array}{l}\text { Shimazaki-Den } \\
{[17]}\end{array}$ & RCT & $\begin{array}{l}2013 ; \\
\text { Japan }\end{array}$ & $3 \%$ DQA & $\begin{array}{l}\text { Artificial } \\
\text { tears }\end{array}$ & $\begin{array}{l}6 \text { times; } \\
4 \text { weeks }\end{array}$ & $\begin{array}{l}\text { Short-BUT- } \\
\text { type DES }\end{array}$ & $17 / 17$ & $2 / 15$ & $2 / 15$ & $44.2 \pm 14.8$ & $44.2 \pm 14.8$ \\
\hline Takamura [18] & RCT & $\begin{array}{l}2012 ; \\
\text { Japan }\end{array}$ & $3 \%$ DQA & $0.1 \% \mathrm{HA}$ & $\begin{array}{l}6 \text { times; } \\
4 \text { weeks }\end{array}$ & DES & $286 / 286$ & $24 / 120$ & $17 / 125$ & $55.3 \pm 17.1$ & $56.9 \pm 16.8$ \\
\hline Miyake [19] & $\mathrm{RCT}$ & $\begin{array}{l}2017 \\
\text { Japan }\end{array}$ & $3 \% \mathrm{DQA}$ & $\begin{array}{l}\text { Artificial } \\
\text { tears }\end{array}$ & $\begin{array}{l}6 \text { times; } \\
4 \text { weeks }\end{array}$ & $\begin{array}{l}\text { DES after } \\
\text { cataract OP }\end{array}$ & $154 / 154$ & $30 / 45$ & $23 / 56$ & $71.7 \pm 7.4$ & $70.3 \pm 7.1$ \\
\hline
\end{tabular}

RCT, randomized controlled trial; DQA, diquafosol; HA, hyaluronic acid; DES, dry eye syndrome; OP, operation; BUT, break-up time.

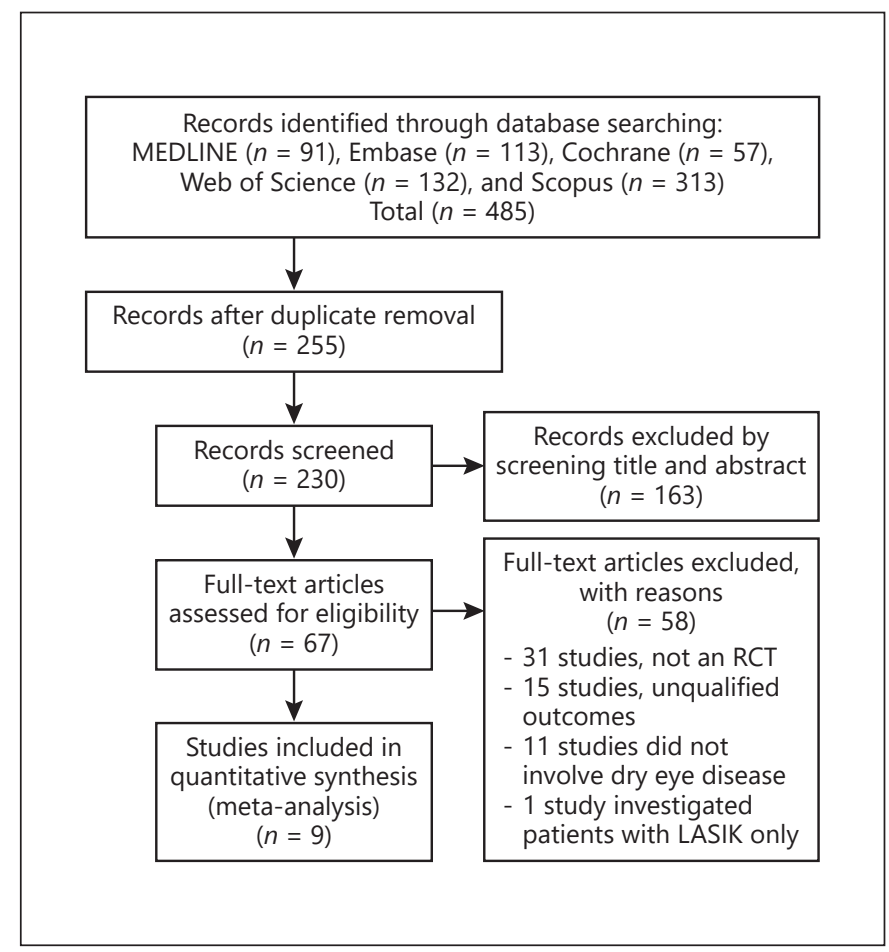

Fig. 1. Flowchart showing the selection of RCTs for inclusion in this meta-analysis. Cochrane, Cochrane Central Register of Controlled Trials; RCT, randomized control trial.

\section{Statistical Analyses}

The main outcome measures were Schirmer score, TFBUT, rose bengal staining score, and corneal fluorescein staining score. We analyzed continuous data using the weighted mean difference (WMD) for the Schirmer score, TFBUT, and rose bengal staining score, and/or the standardized mean difference (SMD) for the corneal fluorescein staining score, to combine trials that measured the same outcome but used different methods. Pooled analyses were done using the generic inverse variance method with random-effects weighting. Data are expressed as WMD or SMD with $95 \%$ confidence intervals (CIs). All outcomes analyzed the change-frombaseline difference. When trials did not report change-from-baseline differences within treatments, these values were imputed from the available data using standard formulae. Heterogeneity between studies was examined using the $I^{2}$ statistic, with values of 25,50 , and $75 \%$ considered low, moderate, and high, respectively [10]. Planned subgroup analyses included length of follow-up (4 weeks, 6-8 weeks, and $\geq 12$ weeks) and type of patients (after ocular surgery vs. no ocular surgery). Statistical analyses were done using Review Manager Software (RevMan 5.3; Cochrane Collaboration, Oxford, UK).

\section{Results}

\section{Identification of Studies}

The searches of the databases resulted in 485 articles (Fig. 1). Of these, 163 publications were excluded, as it was clear from the title and abstract that they did not ful- 


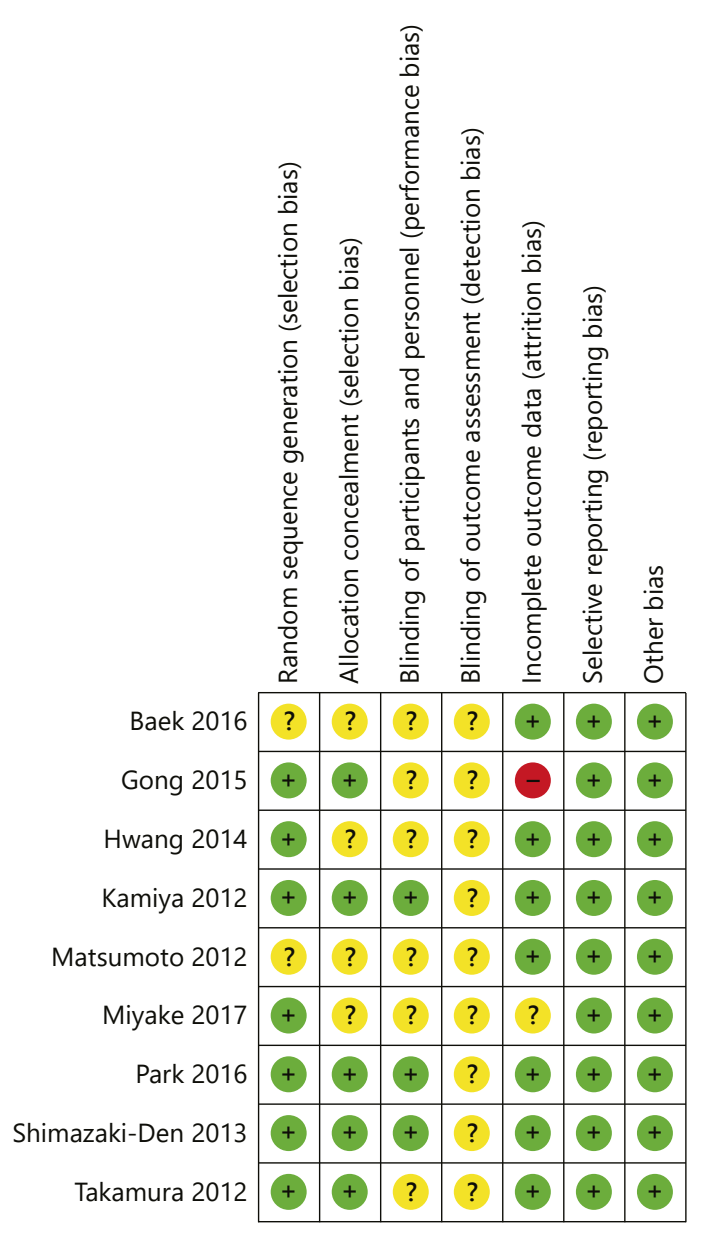

Fig. 2. Risk of bias summary: authors' judgments about each risk of bias item for each study included.

fill the selection criteria. The full texts of the remaining 67 articles were obtained. Following scrutiny, 58 articles were excluded as they were not RCTs $(n=31)$, investigated unqualified outcomes $(n=15)$, did not involve DED $(n=11)$, or investigated only patients with LASIK treatment $(n=1)$. The remaining 9 articles were included (Fig. 1).

\section{Study Characteristics and Patient Populations}

Table 1 summarizes the characteristics of the included trials. All 9 were RCTs published in English [11-18]. Five studies were conducted in Japan, 3 in South Korea, and 1 in Singapore. The studies included 1,467 patients with dry eyes. All studies provided specified criteria for the diagnosis of dry eye. Three studies evaluated the efficacy of diquafosol in dry eye populations after cataract surgery $[11,16,19]$.

In 5 of the studies, topical 3\% diquafosol was compared with sodium hyaluronate eye drops $[12-14,16,18]$. Two studies compared 3\% diquafosol with preservativefree artificial tears $[17,19]$. One study examined $0.9 \%$ normal saline [11] and 1 study used placebo eye drops [15]. Topical 3\% diquafosol was prescribed 4 times daily $[11,13]$ or 6 times daily $[12,14-16,18]$.

\section{Risks of Bias}

The methodological quality of the included studies was generally poor to moderate. The randomization process was described in 7 (77.8\%) of the 9 trials, while only 5 (56\%) had adequate allocation concealment (Fig. 2). The participants and outcome assessments were not blinded in 6 trials.

\section{Overall Outcomes}

The results of the meta-analysis are presented in Figures 3-6. Statistically significant heterogeneity was detected in all of the outcome measures except for Schirmer scores without anesthesia. We confirmed improvement by comparing start point and endpoint. The endpoint was at 4 weeks in 4 studies, at $6-8$ weeks in 2 studies, and at 12 weeks in 2 studies. The three groups were analyzed and compared concerning symptom improvement from the starting point.

The endpoints were different in the 9 studies included. The assessment of long-term results requires more than 8 weeks of clinical trial, but only few studies were conducted over 8 weeks. Therefore, we set the endpoint as the result in the 4 th week, which we confirmed in the results of all studies.

The Schirmer test score without anesthesia was lengthened to $0.74 \mathrm{~mm} / 5 \mathrm{~min}$ (95\% CI: $0.24-1.24, I^{2}=0 \%$ ) in the diquafosol group at 4 weeks compared with the group using other eye drops (Fig. 3). The TFBUT had improved by 0.74 s at 4 weeks ( $95 \%$ CI: $0.40-1.09, I^{2}=99 \%$ ) in the diquafosol group compared with the group using other eye drops (Fig. 4). The fluorescein stain score had improved by 1.14 at 4 weeks (95\% CI: $0.35-1.92, I^{2}=98 \%$ ) in the diquafosol group compared with the group using other eye drops (Fig. 5). The rose bengal stain score had improved by 0.76 at 4 weeks ( $95 \%$ CI: $0.40-1.13, I^{2}=98 \%$ ) in the diquafosol group compared with the group using other eye drops (Fig. 6). There are no reports of toxicity or complications of diquafosol eye drops. 


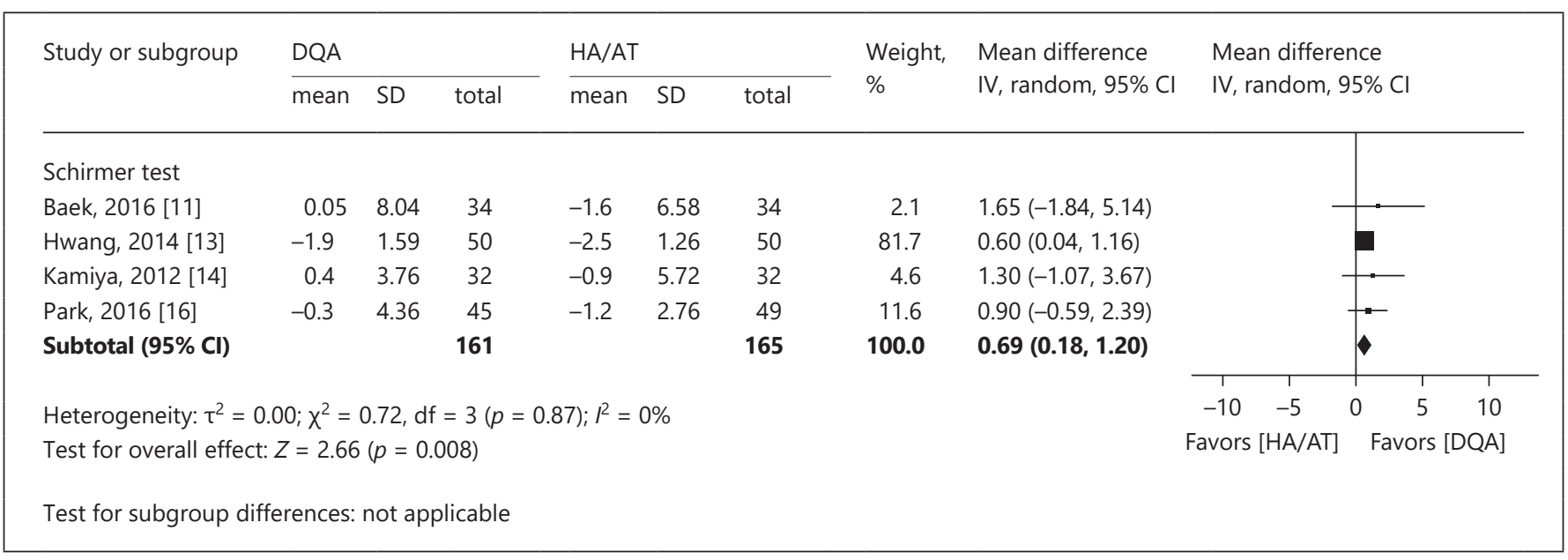

Fig. 3. Schirmer test (without anesthesia) scores in 3\% diquafosol and control groups. DQA, diquafosol; HA/AT, hyaluronic acid/artificial tears; SD, standard deviation; IV, inverse variance; CI, confidence interval.

\begin{tabular}{|c|c|c|c|c|c|c|c|c|c|c|}
\hline \multirow{3}{*}{$\begin{array}{l}\text { Study or subgroup } \\
\text { BUT }\end{array}$} & \multicolumn{3}{|l|}{ DQA } & \multicolumn{3}{|c|}{ HA/AT } & \multirow{3}{*}{$\begin{array}{l}\text { Weight, } \\
\%\end{array}$} & \multirow{3}{*}{$\begin{array}{l}\text { Mean difference } \\
\text { IV, random, } 95 \% \mathrm{CI}\end{array}$} & \multirow{2}{*}{\multicolumn{2}{|c|}{$\begin{array}{l}\text { Mean difference } \\
\text { IV, random, } 95 \% \mathrm{Cl}\end{array}$}} \\
\hline & \multicolumn{2}{|c|}{ mean SD } & \multirow[t]{2}{*}{ total } & \multirow[t]{2}{*}{ mean } & \multirow[t]{2}{*}{ SD } & \multirow[t]{2}{*}{ total } & & & & \\
\hline & & & & & & & & & & \\
\hline Baek, 2016 [11] & 2.81 & 0.82 & 34 & 0.79 & 0.9 & 34 & 13.9 & $2.02(1.61,2.43)$ & & $\rightarrow$ \\
\hline Gong, 2015 [12] & 1.04 & 1.65 & 241 & 0.83 & 1.83 & 248 & 15.1 & $0.21(-0.10,0.52)$ & & $=$ \\
\hline Hwang, 2014 [13] & 1.24 & 0.06 & 50 & 0.48 & 0.03 & 50 & 17.2 & $0.76(0.74,0.78)$ & & - \\
\hline Kamiya, 2012 [14] & 0.9 & 1.5 & 32 & 0.5 & 1.32 & 32 & 10.2 & $0.40(-0.29,1.09)$ & & $=$ \\
\hline Matsumoto, 2012 [15] & 0.6 & 0.17 & 96 & 0.43 & 0.2 & 94 & 17.1 & $0.17(0.12,0.22)$ & & 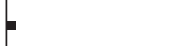 \\
\hline Miyake, 2017 [19] & 0.6 & 1.371182 & 75 & 0.35 & 1.309068 & 79 & 13.7 & $0.25(-0.17,0.67)$ & & $=$ \\
\hline Park, 2016 [16] & 0.76 & 1.8 & 45 & -0.6 & 1.16 & 48 & 11.1 & $1.36(0.74,1.98)$ & & $\rightarrow$ \\
\hline Shimazaki-Den, 2013 [17] & 4 & 3.86 & 9 & 1.16 & 1.11 & 8 & 1.6 & $2.84(0.20,5.48)$ & & $\longrightarrow$ \\
\hline Subtotal $(95 \% \mathrm{Cl})$ & & & 582 & & & 594 & 100.0 & $0.74(0.40,1.09)$ & & $\diamond$ \\
\hline Heterogeneity: $\tau^{2}=0.18 ; x$ & $=487.9$ & $6, d f=7$ & $b<0.0$ & 001); $R^{2}$ & $99 \%$ & & & & $\begin{array}{ll}1 & 1 \\
-4 & -2\end{array}$ & 4 \\
\hline Test for overall effect: $Z=$ & $0(p<$ & $0.0001)$ & & & & & & & vors [HA/AT] & Favors [DQA] \\
\hline
\end{tabular}

Fig. 4. Tear film break-up time (BUT) values in 3\% diquafosol and control groups. DQA, diquafosol; HA/AT, hyaluronic acid/artificial tears; SD, standard deviation; IV, inverse variance; CI, confidence interval.

\section{Subgroup Analyses}

Concerning subgroup analyses, because none of the RCTs reported breakdowns of sex and age, gender and age analyses could not be done. The subgroup analyses involved the operation history (cataract surgery [16]; Fig. 7). Compared to control eye drops, both groups displayed improvements in TFBUT and rose bengal stain test score. The results of the subgroup analysis of topical $3 \%$ diquafosol versus control eye drop type were not statistically significant (online suppl. Table 1). We were un- able to conduct a subgroup analysis based on DED classification because the categories of patients initially recruited were not defined in the majority of the included studies.

A subgroup analysis was performed to confirm the effect of diquafosol on dry eye after cataract surgery (Fig. 7). This analysis showed that TFBUT (SMD $1.21 \mathrm{~s}$ at 4 weeks; 95\% CI: $0.07-2.35, I^{2}=94 \%$ ) and rose bengal stain test score (1.09 at 4 weeks; 95\% CI: 0.59-1.59) improved more with diquafosol than with control eye drops. 


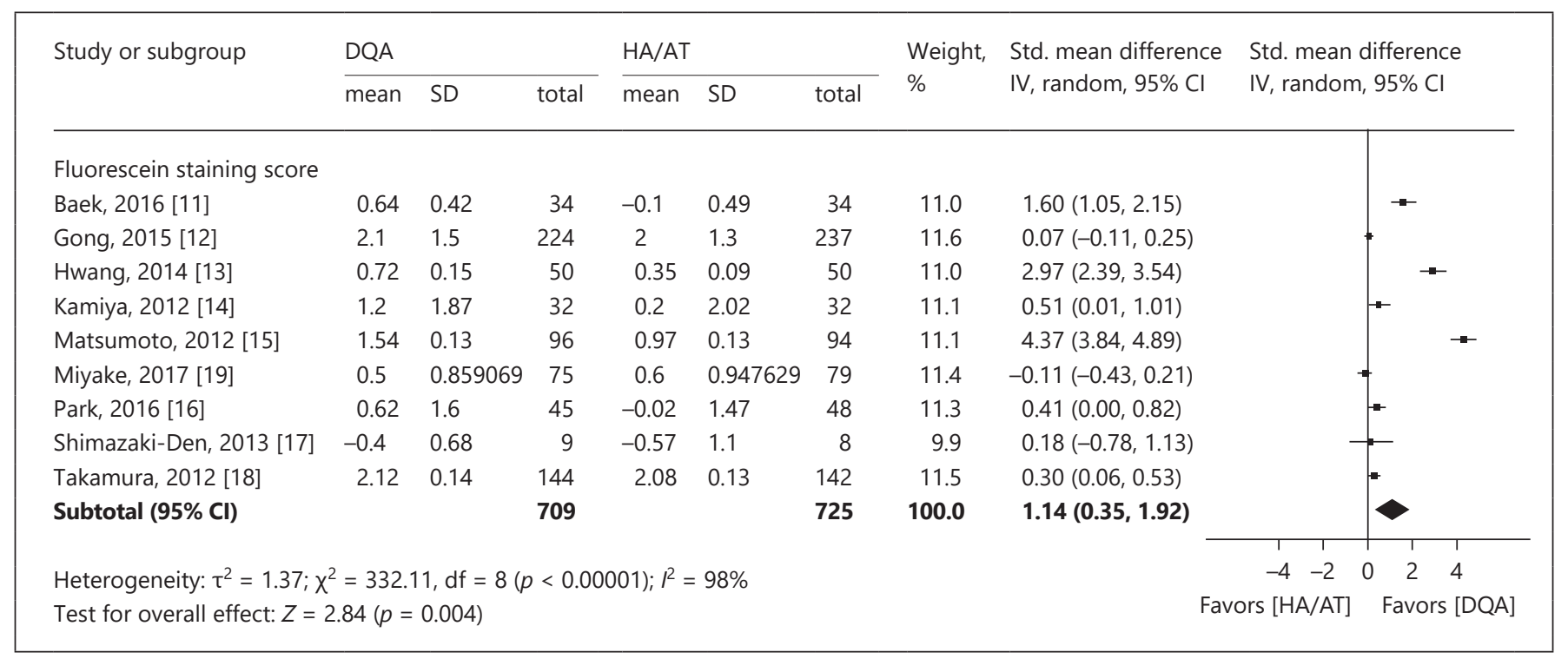

Fig. 5. Cornea and conjunctival fluorescein staining scores in 3\% diquafosol and control groups. DQA, diquafosol; HA/AT, hyaluronic acid/artificial tears; SD, standard deviation; IV, inverse variance; CI, confidence interval.

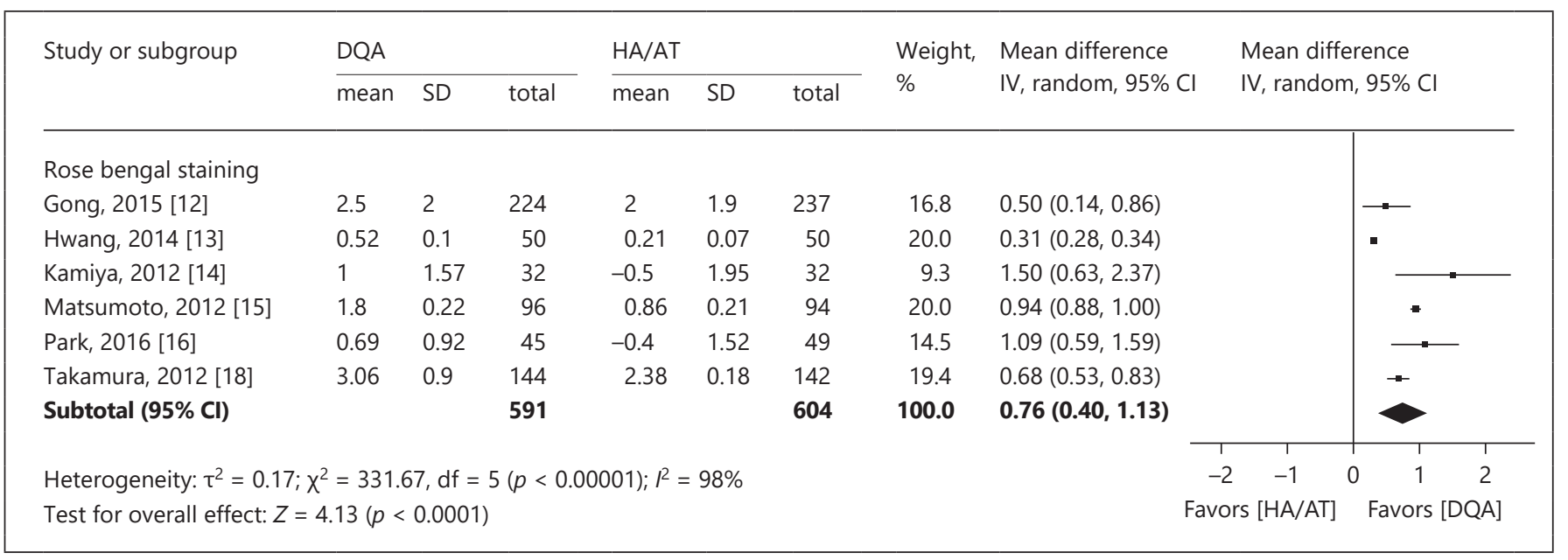

Fig. 6. Cornea and conjunctival rose bengal staining scores in $3 \%$ diquafosol and control groups. DQA, diquafosol; HA/AT, hyaluronic acid/artificial tears; SD, standard deviation; IV, inverse variance; CI, confidence interval.

\section{Discussion}

Dry eye is one of the most common and challenging diseases encountered by eye care practitioners. Ophthalmic diquafosol solutions are therapeutic agents that are suitable for treating the pathogenesis of DED. Conducting a meta-analysis of the effect of $3 \%$ diquafosol eye drops is a clinically important issue, but this has not been done before our study. One systematic review of diquafosol eye drops has been published [20], but it evaluated solutions with variable strengths.

The current systematic review and meta-analysis reveals that topical 3\% diquafosol eye drops significantly improve tear production (according to Schirmer test results), TFBUT, corneal fluorescein staining scores, corneal rose bengal staining and symptom scores, and sub- 


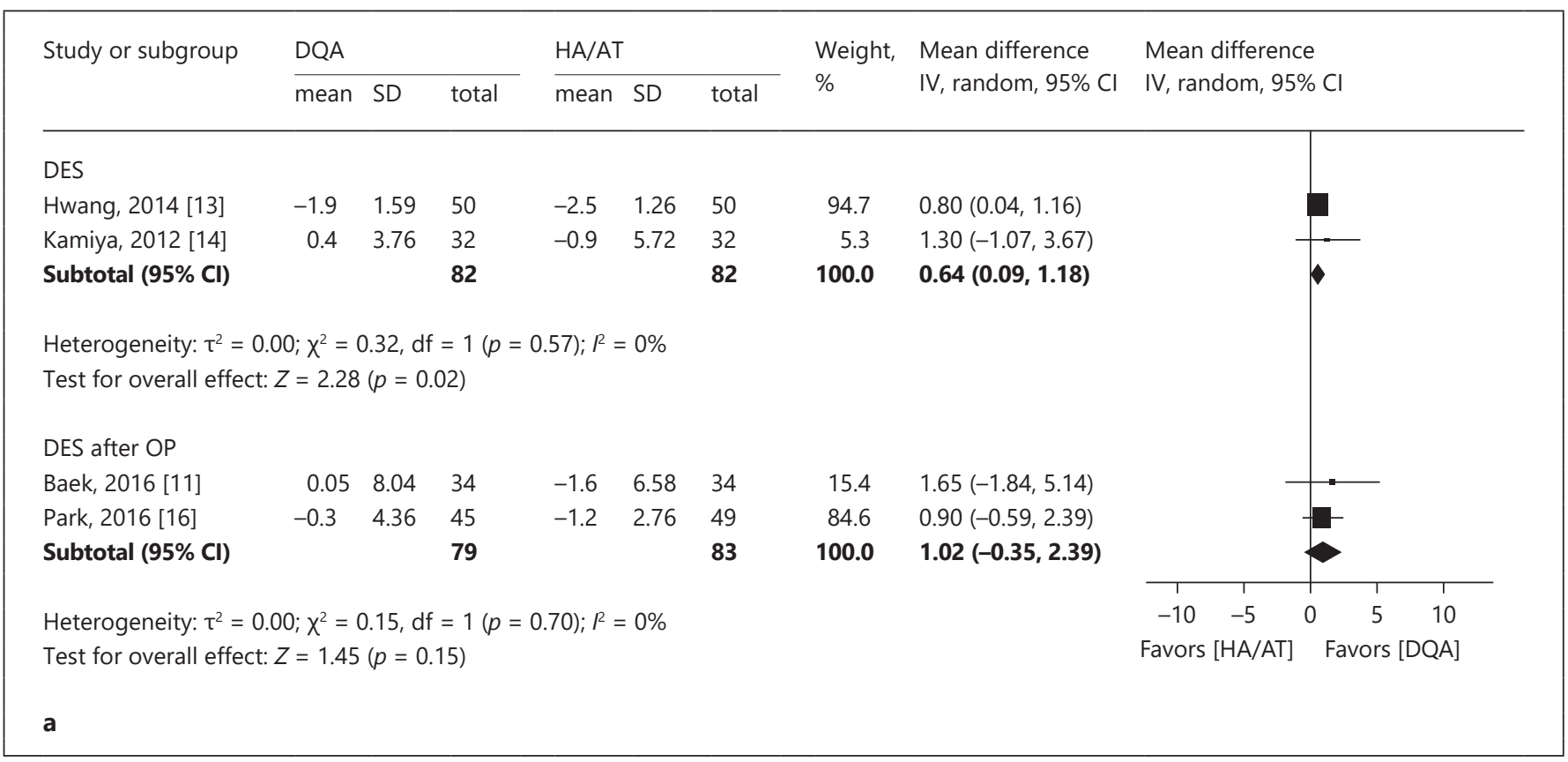

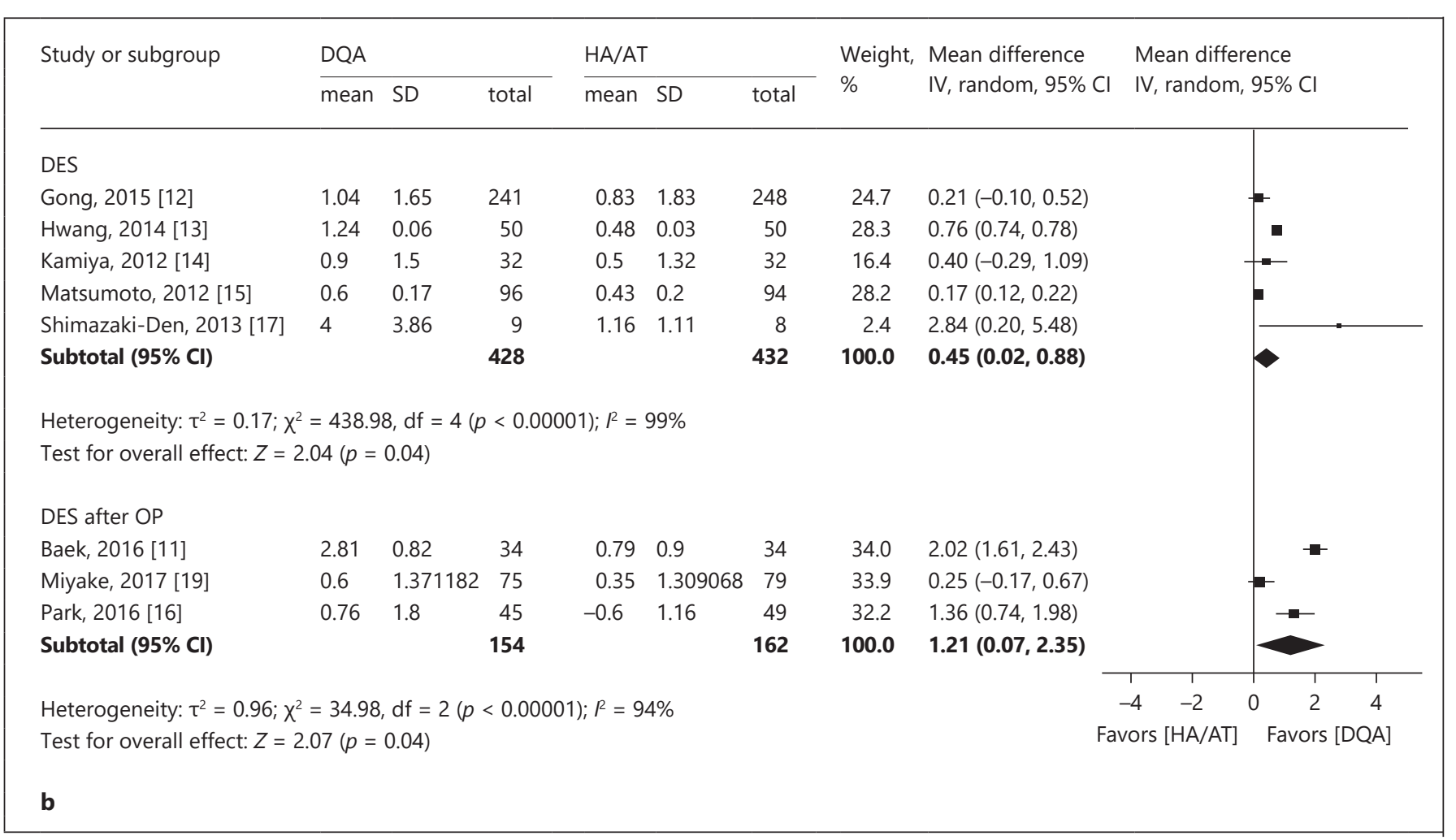

Fig. 7. Subgroup analysis between the no ocular surgery and the cataract surgery (OP) group. a Schirmer test score. b Tear film break-up time. c Fluorescein staining score. d Rose bengal staining score. DQA, diquafosol; $\mathrm{HA} / \mathrm{AT}$, hyaluronic acid/artificial tears; SD, standard deviation; IV, inverse variance; CI, confidence interval; DES, dry eye syndrome.

(Figure continued on next page.) 


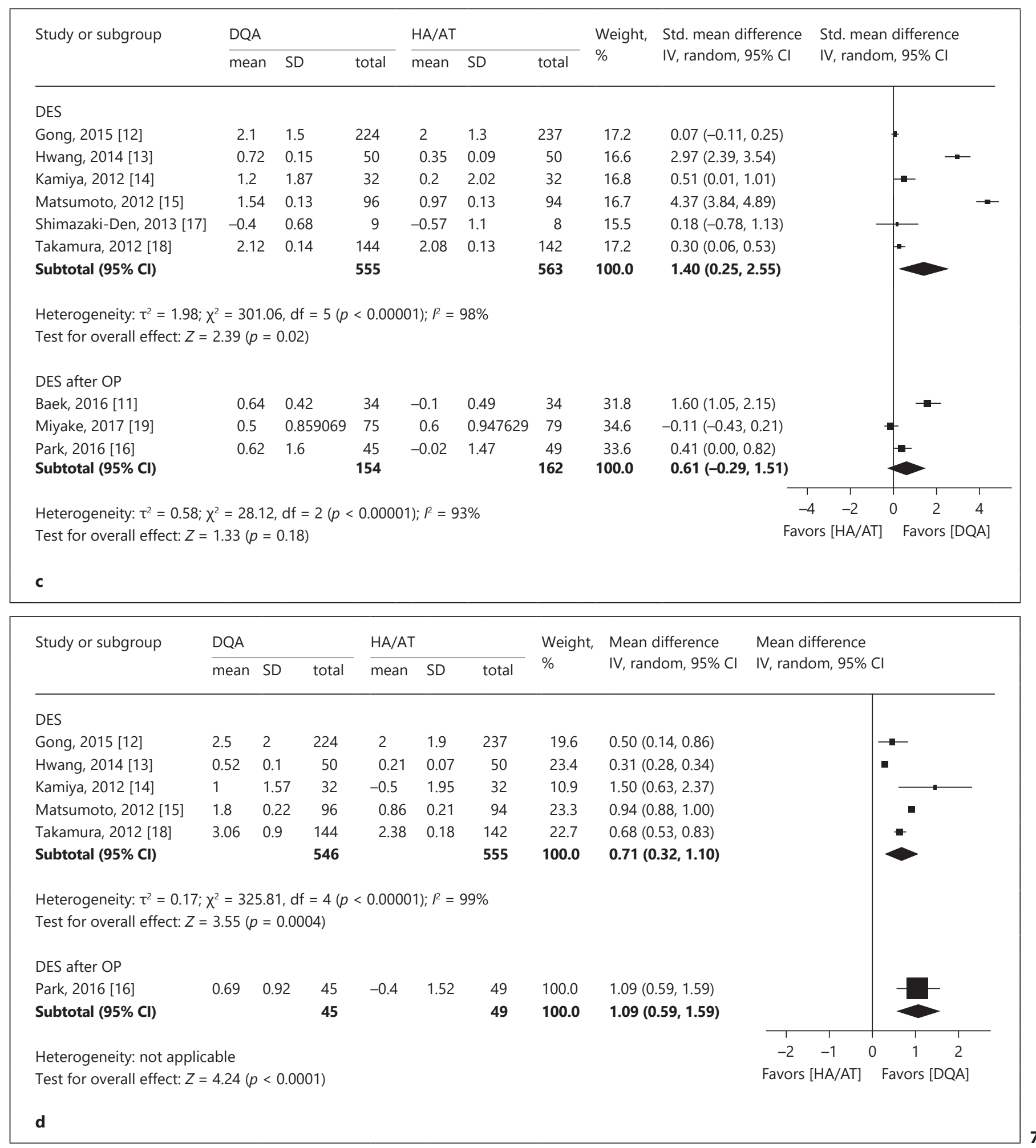


jective symptoms. The findings of our review indicate that compared with placebo, topical 3\% diquafosol is effective in improving scores on the Schirmer test without anesthesia. Diquafosol can increase fluid secretion and hence the tear volume from conjunctival epithelial cells and goblet cells [21].

A significant difference in TFBUT was observed between the topical 3\% diquafosol group and the control group, reflecting an improvement in tear film stability. Whereas the Schirmer test score is related to the tear production status, TFBUT is one of the most commonly employed tests to assess tear film stability [22, 23]. We hypothesize that the improvement in TFBUT is largely due to an increase in goblet cell density. The resultant increased mucin production could improve the interface between the hydrophobic corneal epithelium and the aqueous tear fluid, leading to better tear film stability [24-26].

The subgroup analysis of patients undergoing cataract surgery showed that the diquafosol-treated group had a significant improvement in TFBUT 4 weeks after surgery compared to the control group. In a trial of TFBUT for 2 months after cataract surgery, the TFBUT was significantly reduced after cataract surgery [27]. A link between dry eye and cataract surgery has been reported in the literature. Park et al. [27] evaluated meibomian gland dysfunction, changes in lacrimal tears and ocular surface parameters, and ocular inflammation mediators after cataract surgery. Some studies also reported that meibomian gland dysfunction was worse after cataract surgery, which can lead to dry eye $[27,28]$. Aggravation of meibomian gland dysfunction may be due to chronic meibomian gland dysfunction rather than to the short-term effect of cataract surgery [28]. Many elderly patients who are candidates for cataract surgery might have meibomian gland dysfunction without symptoms [28, 29]. Management of meibomian gland dysfunction is very important after cataract surgery, as a deterioration of dry eye syndrome and deterioration of meibomian gland dysfunction are more likely to affect the outcomes of cataract surgery.

There are several studies showing that the topical application of 3\% diquafosol eye drops improves meibomian gland dysfunction [30,31], and our results of the subgroup analysis also agree with this. In addition, 3\% diquafosol improved the corneal fluorescein staining score more effectively than did sodium hyaluronate. Fluorescein allows the examination of corneal epithelial disorders that result from cell shedding and damaged intercellular spaces in the corneal epithelium [32]. This result could be a secondary effect of the improvement in tear film stability induced by diquafosol. Rose bengal staining also indicates mucin-secreting cells and is used to assess disorders of mucin secretion [33]. Here, the rose bengal staining scores improved significantly with diquafosol treatment. We presume that the improvements in rose bengal staining scores reflect an increase in mucin expression on the ocular surface. In our results, $3 \%$ diquafosol improved the rose bengal staining score more effectively than did sodium hyaluronate. Mucin retains tear fluid and lubricates the ocular surface by converting the corneal epithelial cell surface into a hydrophilic state. If parts of the corneal surface are not fully covered by mucin, corneal epithelial disorders may worsen as a result of low tear retention or reduced ocular surface lubrication [34].

The subgroup analysis showed a significant improvement in rose bengal staining score after cataract surgery. Diquafosol 3\% is effective in stimulating mucin secretion [35], which is consistent with our results.

Symptom scores were self-reported, so different patients may have scored the same intensity of a symptom differently. This subjective assessment makes information bias likely. Still, clinical decisions are usually based on such findings in patient history-taking. Therefore, we regarded this methodology as acceptable. Interestingly, patients treated for 6-8 weeks reported significantly improved symptoms compared to those treated for 4 weeks. This suggests that at least 2 months of treatment are needed to improve symptoms. While no consistent relationship was found between the signs and symptoms of DED, each measurement provides unique information on the ocular surface. Thus, clinical judgment remains important in assessing the response of DED to treatment.

There are several limitations to our review. The first limitation is that the number of studies included in the review is small. In order to increase the accuracy of the meta-analysis, only RCTs were included. Therefore, the number of studies included is small. However, it may be significant for further meta-analyses based on this study. Heterogeneity is another limitation of this study. The included trials recruited populations of all ages and both sexes, covered different regions, and accommodated different types of DED, as well as different types of placebo. The outcome measures, follow-up length and quality, and placebo group treatments also varied between the different trials. These differences might have contributed to the heterogeneity. The type of material used in the comparator groups varied between placebo, normal saline, and hyaluronic acid $0.1 \%$, which is why we performed a subgroup analysis. There were no significant differences between the results; thus, we formed an integrated one-arm 
control and analyzed it. We present the results of the subgroup analysis by different treatment regimens in online supplementary Table 1 . The last consideration is that the relationship between statistically significant differences in values with diquafosol in our analysis (especially, TFBUT and Schirmer test values) and clinical improvement of DED is unclear. There were statistically significant differences, but it is not possible to conclude that these differences are clinically important as compared to the other treatments. Therefore, further trials are needed to determine the clinical relevance of the relationship between symptoms of DED and test values.

Nonetheless, the study has the strength of being the first meta-analysis of the efficacy of $3 \%$ diquafosol. Another strength is its subgroup analysis between no ocular surgery and ocular surgery groups. Several studies have addressed DED related to cataract surgery. Several mechanisms have been proposed to explain the reduction in goblet cell density, including factors associated with the surgical procedure and corneal nerve damage $[36,37]$, after cataract surgery $[38,39]$. Denervation may cause increased tear osmolarity and decreased goblet cell density
[40]. A possible explanation is that topical 3\% diquafosol eye drop therapy aids the ocular surface by a novel mechanism that stimulates water and mucin secretion from conjunctival epithelial cells and goblet cells [21].

\section{Conclusions}

There has been an increased expectation that 3\% diquafosol eye drops provide relief from dry eye syndrome related to ocular surgery. In this regard, our meta-analysis has considerable meaning due to its subgroup analysis. Further research is needed with large-sample-sized RCTs to determine the effectiveness of $3 \%$ diquafosol in dry eye syndrome related to ocular surgery; furthermore, a metaanalysis of those RCTs is expected.

\section{Disclosure Statement}

The authors have no competing financial interests in any of the materials or methods discussed in this study to report.

\section{References}

1 Craig JP, Nichols KK, Akpek EK, Caffery B, Dua HS, Joo CK, et al. TFOS DEWS II definition and classification report. Ocul Surf. 2017 Jul;15(3):276-83.

2 The definition and classification of dry eye disease: report of the Definition and Classification Subcommittee of the International Dry Eye WorkShop (2007). Ocul Surf. 2007 Apr; 5(2):75-92.

3 Tsubota K, Toda I, Yagi Y, Ogawa Y, Ono M, Yoshino K. Three different types of dry eye syndrome. Cornea. 1994 May;13(3):202-9.

4 Management and therapy of dry eye disease: report of the Management and Therapy Subcommittee of the International Dry Eye WorkShop (2007). Ocul Surf. 2007 Apr;5(2): 163-78.

5 Cowlen MS, Zhang VZ, Warnock L, Moyer CF, Peterson WM, Yerxa BR. Localization of ocular P2Y2 receptor gene expression by in situ hybridization. Exp Eye Res. 2003 Jul; 77(1):77-84.

6 Murakami T, Fujihara T, Horibe Y, Nakamura $\mathrm{M}$. Diquafosol elicits increases in net $\mathrm{Cl}-$ transport through $\mathrm{P} 2 \mathrm{Y} 2$ receptor stimulation in rabbit conjunctiva. Ophthalmic Res. 2004 Mar-Apr;36(2):89-93.

7 Jin SW, Min JS. Clinical evaluation of the effect of diquafosol ophthalmic solution in glaucoma patients with dry eye syndrome. Jpn J Ophthalmol. 2016 May;60(3):150-5.
8 Shigeyasu C, Yamada M, Akune Y, Tsubota K. Diquafosol sodium ophthalmic solution for the treatment of dry eye: clinical evaluation and biochemical analysis of tear composition. Jpn J Ophthalmol. 2015 Nov;59(6):415-20.

9 Moher D, Liberati A, Tetzlaff J, Altman DG; PRISMA Group. Preferred reporting items for systematic reviews and meta-analyses: the PRISMA statement. Int J Surg. 2010;8(5): 336-41.

10 Higgins JP, Thompson SG, Deeks JJ, Altman DG. Measuring inconsistency in meta-analyses. BMJ. 2003 Sep;327(7414):557-60.

11 Baek J, Doh SH, Chung SK. The effect of topical diquafosol tetrasodium $3 \%$ on dry eye after cataract surgery. Curr Eye Res. 2016 Oct; 41(10):1281-5.

12 Gong L, Sun X, Ma Z, Wang Q, Xu X, Chen $\mathrm{X}$, et al. A randomised, parallel-group comparison study of diquafosol ophthalmic solution in patients with dry eye in China and Singapore. Br J Ophthalmol. 2015 Jul;99(7): 903-8.

13 Hwang HS, Sung YM, Lee WS, Kim EC. Additive effect of preservative-free sodium hyaluronate $0.1 \%$ in treatment of dry eye syndrome with diquafosol $3 \%$ eye drops. Cornea. 2014 Sep;33(9):935-41.

14 Kamiya K, Nakanishi M, Ishii R, Kobashi H, Igarashi A, Sato N, et al. Clinical evaluation of the additive effect of diquafosol tetrasodium on sodium hyaluronate monotherapy in patients with dry eye syndrome: a prospective, randomized, multicenter study. Eye (Lond). 2012 Oct;26(10):1363-8.

15 Matsumoto Y, Ohashi Y, Watanabe H, Tsubota K; Diquafosol Ophthalmic Solution Phase 2 Study Group. Efficacy and safety of diquafosol ophthalmic solution in patients with dry eye syndrome: a Japanese phase 2 clinical trial. Ophthalmology. 2012 Oct;119(10):1954-60.

16 Park DH, Chung JK, Seo DR, Lee SJ. Clinical effects and safety of 3\% diquafosol ophthalmic solution for patients with dry eye after cataract surgery: a randomized controlled trial. Am J Ophthalmol. 2016 Mar;163:122-131.e2.

17 Shimazaki-Den S, Iseda H, Dogru M, Shimazaki J. Effects of diquafosol sodium eye drops on tear film stability in short BUT type of dry eye. Cornea. 2013 Aug;32(8):1120-5.

18 Takamura E, Tsubota K, Watanabe H, Ohashi Y; Diquafosol Ophthalmic Solution Phase 3 Study Group. A randomised, double-masked comparison study of diquafosol versus sodium hyaluronate ophthalmic solutions in dry eye patients. Br J Ophthalmol. 2012 Oct; 96(10):1310-5.

19 Miyake K, Yokoi N. Influence on ocular surface after cataract surgery and effect of topical diquafosol on postoperative dry eye: a multicenter prospective randomized study. Clin Ophthalmol. 2017 Mar;11:529-40. 
20 Osmond MH, Klassen TP, Wells GA, Correll $\mathrm{R}$, Jarvis A, Joubert G, et al. CATCH: a clinical decision rule for the use of computed tomography in children with minor head injury. CMAJ. 2010 Mar;182(4):341-8.

21 Nakamura M, Imanaka T, Sakamoto A. Diquafosol ophthalmic solution for dry eye treatment. Adv Ther. 2012 Jul;29(7):579-89.

22 Serés C, Quevedo L, Cardona G, Blanch E, Augé M. Tear break-up time for tear film evaluation: are moistening solutions interchangeable? Cont Lens Anterior Eye. 2015 Aug 38(4):272-6.

23 Wan KH, Chen LJ, Young AL. Efficacy and safety of topical $0.05 \%$ cyclosporine eye drops in the treatment of dry eye syndrome: A systematic review and meta-analysis. Ocul Surf. $2015 \mathrm{Jul} ; 13(3): 213-25$.

24 Kaido M, Uchino M, Kojima T, Dogru M, Tsubota K. Effects of diquafosol tetrasodium administration on visual function in short break-up time dry eye. J Ocul Pharmacol Ther. 2013 Jul-Aug;29(6):595-603.

25 Koh S, Ikeda C, Takai Y, Watanabe H, Maeda $\mathrm{N}$, Nishida K. Long-term results of treatment with diquafosol ophthalmic solution for aqueous-deficient dry eye. Jpn J Ophthalmol. 2013 Sep;57(5):440-6.

26 Yokoi N, Kato H, Kinoshita S. Facilitation of tear fluid secretion by $3 \%$ diquafosol ophthalmic solution in normal human eyes. Am J Ophthalmol. 2014 Jan;157(1):85-92.e1.
27 Park Y, Hwang HB, Kim HS. Observation of influence of cataract surgery on the ocular surface. PLoS One. 2016 Oct;11(10):e0152460.

28 Han KE, Yoon SC, Ahn JM, Nam SM, Stulting $\mathrm{RD}$, Kim EK, et al. Evaluation of dry eye and meibomian gland dysfunction after cataract surgery. Am J Ophthalmol. 2014 Jun;157(6): 1144-1150.e1.

29 Arita R, Itoh K, Inoue K, Amano S. Noncontact infrared meibography to document agerelated changes of the meibomian glands in a normal population. Ophthalmology. 2008 May;115(5):911-5.

30 Amano S, Inoue K. Effect of topical 3\% diquafosol sodium on eyes with dry eye disease and meibomian gland dysfunction. Clin Ophthalmol. 2017 Sep;11:1677-82.

31 Ikeda K, Simsek C, Kojima T, Higa K, Kawashima M, Dogru M, et al. The effects of 3\% diquafosol sodium eye drop application on meibomian gland and ocular surface alterations in the $\mathrm{Cu}, \mathrm{Zn}$-superoxide dismutase-1 (Sod1) knockout mice. Graefes Arch Clin Exp Ophthalmol. 2018 Apr;256(4):739-50.

32 Feenstra RP, Tseng SC. Comparison of fluorescein and rose bengal staining. Ophthalmology. 1992 Apr;99(4):605-17.

33 Argüeso P, Tisdale A, Spurr-Michaud S, Sumiyoshi M, Gipson IK. Mucin characteristics of human corneal-limbal epithelial cells that exclude the rose bengal anionic dye. Invest Ophthalmol Vis Sci. 2006 Jan;47(1):113-9.
34 Feenstra RP, Tseng SC. What is actually stained by rose bengal? Arch Ophthalmol. 1992 Jul;110(7):984-93.

35 Choi KE, Song JS, Kang B, Eom Y, Kim HM Immediate effect of $3 \%$ diquafosol ophthalmic solution on tear MUC5AC concentration and corneal wetting ability in normal and experimental keratoconjunctivitis sicca rat models. Curr Eye Res. 2017 May;42(5):66671.

36 Rodriguez AE, Rodriguez-Prats JL, Hamdi IM, Galal A, Awadalla M, Alio JL. Comparison of goblet cell density after femtosecond laser and mechanical microkeratome in LASIK. Invest Ophthalmol Vis Sci. 2007 Jun; 48(6):2570-5.

37 Rodriguez-Prats JL, Hamdi IM, Rodriguez AE, Galal A, Alio JL. Effect of suction ring application during LASIK on goblet cell density. J Refract Surg. 2007 Jun;23(6):559-62.

38 Oh T, Jung Y, Chang D, Kim J, Kim H. Changes in the tear film and ocular surface after cataract surgery. Jpn J Ophthalmol. 2012 Mar; 56(2):113-8.

$39 \mathrm{Li} \mathrm{XM}, \mathrm{Hu} \mathrm{L}, \mathrm{Hu}$ J, Wang W. Investigation of dry eye disease and analysis of the pathogenic factors in patients after cataract surgery. Cornea. 2007 Oct;26(9 Suppl 1):S16-20.

40 Gilbard JP, Rossi SR. Tear film and ocular surface changes in a rabbit model of neurotrophic keratitis. Ophthalmology. 1990 Mar;97(3): $308-12$. 